\title{
Microempresas de artesanía, turismo y estrategias de desarrollo local: retos y oportunidades en una ciudad histórico-patrimonial (Córdoba, España)
}

\section{MSMEs craft, tourism and local development strategies: challenges and opportunities in a historical-heritage city (Córdoba, Spain)}

\author{
Manuel Rivera Mateos ${ }^{1}$ y Ricardo D. Hernández Rojas ${ }^{2}$
}

\begin{abstract}
RESUMEN
Este trabajo tiene por objeto el estudio de los talleres y establecimientos de productos artesanales típicos en un destino de turismo urbano cultural como es la ciudad de Córdoba, con varias declaraciones como Patrimonio de la Humanidad, centrándose en las relaciones y sinergias existentes entre estos, la dinámica urbana y socioeconómica reciente y su oferta turística. Igualmente se analiza la localización geográfica de estos establecimientos, las categorías de productos comercializados, sus condiciones de acceso al mercado local y su visibilidad real en la oferta turística local a través de rutas, centros especializados de comercialización, visitas a talleres u otros medios instrumentales. Del análisis realizado se desprende que, pese a las importantes potencialidades de la artesanía tradicional para la consolidación y posicionamiento de la imagen de Córdoba como destino excelente de turismo cultural, existe un nivel bajo de integración y vinculación entre los negocios artesanos, la propia ciudad y la oferta turística urbana, lo que exige una redefinición de sus estrategias comerciales y de sostenibilidad y su adecuada inserción en la cadena de valor de la oferta comercial y turística local. Finalmente se aportan algunas propuestas de gestión estratégica público-privada en este sentido.
\end{abstract}

1 Universidad de Córdoba manuel.rivera@uco.es ORCID iD: http://orcid.org/0000-00032780-380X.

2 Universidad de Córdoba et2heror@uco.es ORCID iD: http://orcid.org/0000-0002-30552151.

Copyright: ( 2018 CSIC. Este es un artículo de acceso abierto distribuido bajo los términos de la licencia de uso y distribución Creative Commons Reconocimiento 4.0 Internacional (CC BY 4.0). 
Palabras Clave: artesanía; turismo; microempresas; desarrollo local; Córdoba (España).

\section{Abstract}

This paper aims at studying workshops and establishments specialized on typical handcraft products in an urban touristic destination such as Córdoba. The study focuses on the synergies and connections of those with its recent urban and socioeconomic dynamics and the tourist activity of the city. In the same way it is analyzed the geographic location of those establishments, the categories of the marketed products and its real visibility in the local touristic offer through different routes, specialized establishments, visits to different workshops and other channels. From the analysis carried out, we infer that despite the important potentials of the traditional handicraft for the consolidation and positioning of Cordoba as an excellent cultural tourist destination, there is low integration or link between handicraft businesses, the city and the urban touristic offer. This requires a redefinition of its commercial and sustainable strategies and an adequate inclusion into the value chain of the touristic and commercial offer of the city. Finally, some proposals of public-private strategic management are provided.

KeY wORDS: crafts; tourism; micro-enterprises; local development; Córdoba (Spain).

Cómo citar este artículo / Citation: Rivera Mateos, M. y Hernández Rojas, R. D. (2018): "Microempresas de artesanía, turismo y estrategias de desarrollo local: retos y oportunidades en una ciudad histórico-patrimonial (Córdoba, España)", Estudios Geográficos, LXXIX/285, pp. 529-553. https://doi.org/10.3989/estgeogr.201820.

\section{INTRODUCCIÓN}

En este artículo se estudian las relaciones entre el turismo urbano y cultural y los talleres y establecimientos comerciales de artesanía de la ciudad de Córdoba (España), con el objeto de determinar la existencia de un segmento de mercado de los productos artesanales bien orientado hacia el turismo, el nivel de integración y sinergias entre los puntos de venta y fabricación y la oferta turística local, así como su contribución a una experiencia de calidad por parte de los visitantes y la obtención de beneficios reales procedentes del desarrollo turístico por parte de los actores artesanos implicados.

Para la comprensión de las relaciones e interacciones de quienes participan de la cadena de comercialización y distribución de productos artesanales en el marco del turismo cultural urbano, se utiliza el concepto de "cadena de valor» desarrollado desde la economía y aplicado al análisis geográfico de los sistemas comerciales así como el enfoque de la dinámica relacional (Clocke, Crang y 
Goodwin, 2011). De esta manera, se pretenden identificar los elementos necesarios para explicar el fenómeno que vincula los dos sectores de actividad (la artesanía tradicional y el turismo), así como para aproximarnos al turismo cultural desde la perspectiva - muy poco estudiada aún- de las potencialidades de un recurso patrimonial singular e identitario como es la artesanía tradicional y la funcionalidad de su puesta en valor turístico como instrumento para el desarrollo local.

Partimos de la hipótesis de que los establecimientos artesanales están intentando responder a la nueva coyuntura socioeconómica de la ciudad y sus profundos cambios, ofertando un surtido exclusivo y diferencial de productos de artesanía de calidad, pero sin saber aprovechar numerosas potencialidades por la falta de una estrategia de integración comercial y productiva con la oferta y la demanda turística y por la inexistencia o insuficiencia de políticas públicas de acompañamiento. Para la confirmación de esta hipótesis se ha intentado conocer la visión que tienen los artesanos, los establecimientos de venta y algunos agentes locales implicados (stakeholders) sobre las oportunidades de la vinculación y de las sinergias entre ambas actividades económicas, el grado de implicación que tienen con su entorno urbano y la oferta turística, así como el potencial que pueden tener en la revitalización comercial y turística del casco histórico y otras áreas adyacentes aquejadas de una pérdida de centralidad comercial.

A lo largo de la investigación hemos comprobado que esta temática de estudio relacionada con la importancia de la producción y el comercio de la artesanía en el buen funcionamiento del territorio urbano, de sus áreas comerciales tradicionales y del desarrollo de la actividad turística en sus centros históricos, apenas ha sido objeto de reflexión en la bibliografía española, a diferencia de diversos destinos urbanos y rurales de países pobres y en vías de desarrollo (en adelante PPVD), por lo que el análisis empírico que realizamos puede contribuir a un mejor conocimiento de las dinámicas de desarrollo del turismo cultural desde una perspectiva más integral en destinos maduros, así como de la puesta en valor de los recursos patrimoniales identitarios que tanto pueden contribuir a afianzar la imagen turística y de marca de los destinos urbanos.

LAS RELACIONES DE COMPLEMENTARIEDAD «TERRITORIO, ARTESANÍA Y TURISMO»

La artesanía tradicional se ha convertido en un elemento consustancial, por su atractivo y su carácter cultural identitario, de la oferta turística de destinos 
de todo tipo, tanto urbanos como rurales y litorales, emergentes o maduros y de PPVD (Essayad, 2011; Horjan, 2011; Gustami, Kusuma y Heru, 2014; Afra, 2016; Jha y Nath, 2015) e incluso de países desarrollados y de una dilatada trayectoria turística (Kosianski, 2005; Espinosa, 2009; Richards, 2013; Maruya, Yamahita y Uchiyama, 2015; Gazimagomedov, 2017). En coherencia tanto con el reconocimiento del valor patrimonial de la artesanía como de su trascendencia socioeconómica, hay experiencias muy antiguas de protección y fomento de este sector de actividad en países asiáticos como Japón o Corea del Sur (Hirotsugu, 2005). Y particularmente en América Latina, donde la artesanía mantiene una importancia socieconómica fundamental en las formas de vida y de producción tradicionales de muchas comunidades, esta actividad cuenta en muchos países con un marco institucional de protección y fomento a través de políticas públicas que ven también al turismo como un instrumento clave para su desarrollo y sostenibilidad (Uribe, 2011). Hay que tener en cuenta que los artesanos en América Latina representan en torno a una cuarta parte de las microempresas existentes y generan un efecto social y multiplicador de primera magnitud, particularmente en países de gran tradición artesanal como Colombia, Argentina, Chile, Ecuador, Perú, Bolivia, Méjico, República Dominicana, Brasil o Cuba (Benítez, 2010; Uribe, 2011), que, en general, están cada vez mejor posicionados en los mercados turísticos nacionales e internacionales. En este contexto las nuevas dinámicas globales parecen estar identificando en el sector artesanal latinoamericano - como también en otros destinos- una serie de desafíos y oportunidades comunes que hacen que la artesanía pueda revivir y transformarse cuando encuentra nuevos mercados y es capaz de competir en ellos, como es el caso del turismo (Fernández y Ramos, 2005; Mincomercio, 2006; Hernández-Girón, Yexcas y Domínguez-Hernández, 2007; Rivera et al., 2008; Santana y Ricci, 2009; Oliveira et al., 2013; Rodrigues, Sousa y Vasconcelos, 2014; Fernández de $\mathrm{Paz}, 2014)$.

En el caso de países como España, con una dilatada y rica tradición artesanal, esta actividad está experimentando en las últimas décadas un proceso de recuperación y de cambio, derivado del decurso temporal reciente, paralelo a diversas alteraciones de la coyuntura y el sistema socioeconómico general (Freire, 2004) y a través de un proceso plural y complejo en el que están interviniendo numerosos agentes, incluidos los vinculados directa o indirectamente con el sector turístico. Tanto es así que el estudio del patrimonio y de las actividades artesanales está generando una línea de investigación relativamente productiva, aunque reciente, en lo que respecta sobre todo al análisis de la interacción entre la globalidad y las culturas tradicionales y los 
aspectos patrimoniales, culturales y etnográficos de la artesanía (Rodríguez, 2006), si bien mucho menos abundante en lo que se refiere a las interacciones y sinergias turismo-artesanía-territorio. De hecho, pese a las numerosas experiencias más o menos exitosas que podemos encontrar a lo largo y ancho de la geografía española, tales como las rutas turístico-artesanales de las ciudades Patrimonio de la Humanidad de Ubeda y Baeza (Jaén), los centros artesanos especializados de Talavera de la Reina o La Alcarria en Castilla-La Mancha y Valle de Ibai-Eder (País Vasco), o las célebres ferias y mercados artesanales de Olot (Cataluña) y Galicia, es muy escasa la bibliografía existente de estudios de caso con perspectiva pluridisciplinar, económico-artesanal, patrimonialetnográfica y turística, aún cuando podamos encontrar información de los mismos en los medios convencionales de promoción y comercialización turística (Hernández, 2002; González, 2003; Freire, 2004; Instituto de Turismo de Murcia, 2007; Tresserras, 2008).

El término recientemente acuñado de Craftourism en la bibliografía anglosajona (Greg, 2013; Baksi, 2015a) ilustra la creciente integración de la artesanía con la oferta turística y los esfuerzos de no pocas organizaciones de gestión y promoción de destinos turísticos $(D M O)$ para asociar los valores de la artesanía local con el imaginario turístico de los mismos, potenciando la experiencia satisfactoria de los visitantes, la fidelización de estos y el aumento del atractivo de los territorios (Baksi, 2015a y 2015b). Y aún cuando no podamos hablar con propiedad de una tipología turística o segmento de demanda turística, lo cierto es que la artesanía tradicional se ha convertido en un instrumento muy útil para agregar valor y capacidad competitiva y diferencial a los destinos turísticos, así como para optimizar la práctica de diversas formas de turismo como el cultural, el de compras, el rural, etnográfico e indígena o el industrial, en cuyos contextos se han realizado en los últimos años algunas aproximaciones a la artesanía y su puesta en valor como recurso y producto turístico (Virassamy y Levêque, 2005; Froehlich y Alves, 2007; Perlès, 2007; Tresserras, 2008; Iuva y Ciliane, 2015).

Es cierto que la artesanía no constituye la mayoría de las veces la principal motivación de la visita en muchos destinos pero no cabe duda de que al menos se conforma como un producto complementario bastante atractivo en muchos casos y fuertemente diferenciador y representativo de determinados destinos visitados. Unas veces se convierte en un objeto apreciado de compras y souvenir indispensable para turistas sensibilizados culturalmente y de cierto poder adquisitivo (Santana y Ricci, 2009; Iuva y Ciliane, 2015); otras veces los productos artesanales son utilizados en la decoración e interiorismo de establecimientos turísticos (hoteles rurales, "hoteles con encanto" u 
hoteles boutique) con determinadas señas diferenciales (Rodrigues, Sousa y Vasconcelos, 2014), y cómo no, también pueden convertirse en el eje central de algunas rutas turístico-culturales y experienciales (Kosianski, 2005; Gazimagomedov, 2017) y otros productos turísticos como visitas a talleres con demostraciones artesanales en vivo, centros museísticos, zocos, mercadillos y centros artesanales, ferias y exposiciones, kioscos y tiendas en servicios de información turística y recepción de visitantes, etc. (Prost y Givre, 2005; Perlès, 2007). Si además tenemos en cuenta la evolución reciente del turismo, tan ligado frecuentemente a la búsqueda de motivaciones culturales y vitales, de experiencias diferentes o genuinas, etc., podemos entender fácilmente que la artesanía pueda convertirse en un factor de interés común que conjuga muy bien con dichas motivaciones, todo ello sin perjuicio de que las experiencias ligadas a las demostraciones en vivo de los talleres artesanos y su acervo cultural tradicional, por ejemplo, si se articulan bien con su entorno cultural, paisajístico y geográfico como lugar de producción que es y con el resto de la oferta turística local o regional, puedan llegar a convertirse en una atracción fundamental con capacidad de generación propia de algunos flujos turísticos nada desdeñables (Nason, 1984; Holder, 1989; Freire, 2004; Rivera et al., 2008; Espinosa, 2009; Oliveira et al., 2013; Richards, 2013; Terziyska, 2013; Rodrigues et al., 2014).

No es extraño, en fin, que diversos organismos internacionales hayan prestado en los últimos años una atención específica a las sinergias turismoartesanía como un importante instrumento de desarrollo local y comunitario, así como de empoderamiento de mujeres rurales y colectivos desfavorecidos, generación de empleo y lucha contra la pobreza, particularmente en PPVD. De hecho, el fomento de la artesanía y su integración en la oferta turística se ha convertido en una de las estrategias del denominado Pro-poor tourism (PPT), que intenta incrementar a través del turismo las oportunidades de la población desfavorecida de los PPVD (Ashley, Roe y Goodwin, 2001), tanto en lo que se refiere a los beneficios económicos como a su participación en los procesos de toma de decisiones sobre el desarrollo turístico; ideas estas que han sido incorporadas al programa ST-EP de la Organización Mundial del Turismo (OMT, 2008) y sus proyectos demostrativos de turismo y artesanía como los de las provincias de Guizhou, en China (Yang, 2006) y Ha Tay, en Vietnam (Duond, 2015), analizados expresamente en la Conferencia Internacional de Turismo y Artesanía de la OMT en Teherán (Irán) en 2006 (OMT, 2008). Y, por otro lado, la propia UNESCO, además de reconocer la importancia singular de la artesanía dentro del vasto campo de las industrias culturales y en el conjunto del patrimonio material e inmaterial de las culturas autóctonas, se ha 
interesado por esta actividad como fenómeno socioeconómico y por su puesta en valor y sostenibilidad mediante su integración adecuada en la oferta de los destinos turísticos (Bouchart, 2004).

El turista cultural especializado y de calidad, que busca formas más experienciales de hacer turismo y más cognitivas y placenteras, establece muchas veces el contraste y la diferencia entre su entorno urbano e industrial de origen y el destino visitado para encontrar autenticidad, tradición, monumentalidad, formas de producción alternativas, naturaleza y la mano extendida del "otro", de manera que no quiere virtualidad sino realidad. Pues bien, estos turistas son, de hecho, consumidores potenciales de la artesanía, ya que esta puede jugar un papel representativo muy fuerte de la cultura del destino visitado por su carácter fuertemente identitario (MacCannell, 1984; Nason, 1984; Holder, 1989). Y esto vale no solo para la artesanía tradicional del lugar, sino también para la artesanía de autor y la artesanía postindustrial, realizada de manera mixta con procedimientos singulares de los oficios tradicionales y su conjunción con técnicas y diseños innovadores y más actuales

Los cambios de las décadas de los ochenta y noventa del siglo XX que permearon otras esferas de la sociedad, de la economía y los hábitos de vida, constituyen y sitúan el marco temporal de punto de encuentro de los sectores del turismo y la artesanía dando lugar a una modalidad específica de turismo cultural. Hoy día, como resultado también de la industrialización y la globalización, muchos turistas buscan nuevas señas de identidad en las sociedades postmodernas, de manera que la artesanía genuina y tradicional se ha convertido en un instrumento de búsqueda de las mismas y, además, identifica a las poblaciones y los territorios, por lo que incluso se utiliza como importante elemento de promoción turística (Iuva y Ciliane, 2015). No es extraño entonces que la relación «lugar-artesanía» haya sido utilizada en turismo para dicha promoción en lo que respecta a la utilización de distintivos de los productos artesanos típicos, tanto nacionales como regionales. Los turistas y los consumidores en general son hoy por hoy cada vez más conscientes de lo que consumen y de su relación con el medio en el que viven, lo que ha incrementado la demanda de consumo de los productos locales en línea con las tendencias de los nuevos estilos de vida más saludables y la defensa de valores éticos y sostenibles en relación con los territorios, los paisajes, la cultura local o los productos típicos y tradicionales, que precisamente constituyen una de las espinas dorsales del turismo cultural (Hall y Page, 1999; Horjan, 2011; Vizcaíno, 2015).

En este contexto los productos artesanales se ponen de moda por su calidad, su elaboración genuina y tradicional, su carácter local y auténtico al 
ser producidos por pymes o micropymes, su oferta limitada y no seriada y su propia exclusividad (MacCannell, 1984; Ballester, 1996; International Trade Center, 2010; Iuva y Ciliane, 2015), al estar disponibles únicamente o en la mayor parte de los casos en los establecimientos de venta y/o talleres de los propios artesanos. Por todo esto se debería profundizar en las buenas prácticas y los estudios de caso del turismo cultural y en su interrelación y maridaje con la artesanía a través de rutas o recorridos turísticos, focos de venta (zocos, plazas, centros especializados, ferias y exposiciones ) u otros medios, pero siempre desde la perspectiva de conectar al turista con el «saber hacer» (experiencias) del artesano y no como un simple recorrido comercial. De esta manera, se podría posicionar a los artesanos como unos actores importantes del destino turístico, tanto desde el punto de vista del interés real de sus producciones como desde su «saber hacer» y su vinculación identitaria con el territorio. Todo esto sin perjuicio de la necesidad, también, de establecer una cadena de valor de los productos artesanales mediante el reforzamiento de sus vínculos comerciales con el turismo, tanto verticales como horizontales (agrupaciones de productores y asociaciones), pues, de hecho, están generando buenos resultados en algunos destinos (International Trade Centre, 2010).

Normalmente los actores de la cadena de abastecimiento y comercialización de productos artesanales —más aún al ir perdiendo estos su función utilitaria y doméstica tradicional - tienen una demanda local cada vez más reducida, pero pueden entrar en el mercado del turismo cultural y percibir este como una oportunidad de negocio. No obstante, han de darse una serie de factores y premisas previas como una localización adecuada en la cadena referida en términos de conectividad, infraestructura y adecuación turísticas, acceso a la información y a la cobertura de promoción turística del destino y determinados vínculos con otros actores de proximidad (productores y consumidores potenciales) y con organizaciones con las que crear redes colaborativas, además de una estrategia promocional turística relacionada más específicamente con el sector de la artesanía. Todos estos aspectos son fundamentales para la viabilidad del turismo cultural-artesanal y constituyen la base fundamental para las nuevas formas de comercialización, organización y relación de la cadena comercial de la ciudad. En este sentido, hemos de referirnos a las marcas, distintivos de calidad e indicaciones geográficas, que pueden jugar un papel importante en el proceso de creación de valor, diferenciando el origen vinculado al producto de otros de la misma categoría. Estas integran, por tanto, en su definición, no solo el origen geográfico sino, de una forma relevante, la tradición y especialización a la hora de elaborar productos de alta calidad y con personalidad diferente. 
Los operadores de la cadena de suministro con el fin de adaptarse a la demanda del mercado y responder de manera proactiva a las exigencias de calidad por parte de los consumidores, se apoyan en este valor añadido como sello de distinción de productos con atributos específicos. Y los establecimientos de artesanía, en la medida en que muestran y comercializan los productos de las marcas y denominaciones geográficas de protección y calidad, actúan como instrumento relacional importante entre los productores y consumidores fuera muchas veces del lugar de producción. De hecho, los turistas acaban comprando estos productos y los trasladan desde los destinos visitados y lugares de origen y/o producción hasta sus domicilios, donde son consumidos a modo de souvenirs como forma de consumo turístico (Richards, 2013).

Por otra parte, la venta directa in situ asociada a actividades turísticas o de ocio se está convirtiendo precisamente en un nicho de mercado característico de la artesanía local que surge por la necesidad de diversificación de la oferta de los pequeños talleres y comercios minoristas de artesanía. De esta manera, surgen también diversas estrategias de comercialización de productos artesanales a través, sobre todo, de rutas y tours temáticos asociados a un producto o varios oficios artesanos de una determinada zona geográfica y/o de rutas étnico-culturales o históricas de diversos productos y reclamos asociadas al turismo identitario. La información acerca de los productos especializados y autóctonos encuentra precisamente aquí un medio instrumental y un espacio de interacción adecuado para acercar a los diferentes actores en la cadena, conectar directamente los productores con los talleres y tiendas y los turistas o excursionistas (Tresserras, 2008), invitando a estos a visitar el destino y disfrutar de experiencias en su entorno paisajístico y cultural.

La CONTEXTUAlización de CóRdoba COMO DESTiNO DE TURismo CUltural y zONA DE INTERÉS ARTESANAL: ENCUENTROS Y OPORTUNIDADES

Córdoba es una ciudad de interior situada en la región más meridional de España y cuenta con una ubicación privilegiada en cuanto a comunicaciones tanto por tren de alta velocidad (AVE) como por carretera. El sector servicios es el que tiene carácter mayoritario en su economía local y dentro de este la principal actividad económica es el turismo, que después del estancamiento motivado por la crisis económica ha vuelto a ser el principal motor económico y el primer sector en comenzar a salir visiblemente de la misma, de manera que desde las instituciones locales se han priorizado una serie de medidas 
para la planificación estratégica y el fomento de esta actividad, la atracción y fidelización de turistas, la diversificación de los mercados emisores y los segmentos de demanda y la mejora de la competitividad y sostenibilidad de las empresas turísticas (Escuela de Organización Industrial, 2014). Asimismo, cuenta actualmente con un Plan Turístico de Grandes Ciudades en ejecución, conveniado entre las Administraciones Local y Regional, que intenta favorecer el desarrollo de esta actividad creando nuevos productos y equipamientos turísticos que mejoren y diversifiquen la oferta existente.

Córdoba despunta, asimismo, a nivel nacional como destino cultural dentro de la Red de Ciudades Patrimonio de la Humanidad, con cuatro declaraciones oficiales que la han convertido en la ciudad española más distinguida por la UNESCO: en 1984 la Mezquita-Catedral; en 1994 el casco histórico de la ciudad, que posee una gran riqueza monumental y conserva grandes vestigios de la cultura romana, musulmana, judeo-sefardí y cristiana; en 2012 la Fiesta de los Patios Populares, reconocida como Patrimonio Inmaterial de la Humanidad y recientemente, en 2018, el Conjunto Arqueológico de origen musulmán de Medina Azahara. Por otra parte, cuenta con unos de los Conjuntos HistóricoArtísticos de mayor extensión de Europa (246,73 ha), declarado Bien de Interés Cultural (BIC). Estos reconocimientos hacen de esta ciudad de interior un lugar de gran atractivo para ser visitada por su rico y diverso patrimonio cultural, tanto material como inmaterial, y dentro del mismo debemos de considerar su artesanía tradicional, mezcla de herencias culturales diversas, de gran singularidad y calidad en muchos casos y con algunos oficios artesanos, técnicas y modalidades que se han preservado casi exclusivamente en este entorno territorial como la platería de filigrana cordobesa, la orfebrería de oro y plata, el cuero repujado de cordobanes y guademecíes o la cerámica califal de origen árabe. No es una casualidad, en este sentido, que Córdoba, conjuntamente con las ciudades de Sevilla y Granada con las que conforma el principal eje de turismo cultural de Andalucía, se encuentre entre los primeros puestos en el ranking de capitales de provincia con mayor número de talleres de artesanía tradicional ${ }^{3}$

El importante crecimiento de la oferta alojativa, de restauración y de servicios turísticos en la ciudad ha sido muy positiva para la demanda de productos artesanales típicos, pues de hecho la gran mayoría de los talleres

3 Un total de 38 según datos obtenidos de la explotación específica del Registro de Artesanía de Andalucía (Junta de Andalucía), si bien en el trabajo de campo realizado para este estudio, hemos podido elevar la cifra a más de 50, incluyendo artesanos no inscritos (la inscripción en este Registro es de carácter voluntario) y algunas tiendas comerciales y de souvenirs.

Estudios Geográficos, Vol. LXXIX, 285, pp. 529-553, julio-diciembre 2018

ISSN: 0014-1496, eISSN: 1988-8546, doi: https//doi.org/10.3989/estgeogr.201820 
y tiendas de artesanía se ubican en las zonas del Conjunto Histórico con mayores flujos turísticos, como veremos más adelante. La especialización y diversificación artesanal de las zonas más turísticas de este Conjunto Histórico ha abierto nuevas perspectivas para su comercio tradicional, que ha sufrido un declive apreciable en las últimas décadas paralelamente a los procesos de turistificación y despoblamiento demográfico, de manera que ha facilitado, al menos, la revalorización de su espacio urbano comercial con problemas de sostenibilidad frente a los nuevos ejes comerciales centrales o semicentrales y las grandes superficies comerciales suburbanas de su estructura urbana.

Obviamente estos establecimientos venden un limitado rango de productos no seriados y poco comunes que no suelen encontrarse en grandes centros comerciales y establecimientos convencionales. Por tanto, no tienen grandes volúmenes de ventas, sino que se dedican a vender productos especializados, diferenciales y de alto valor añadido, de «elaboración excepcional» y de «identificación propia». Pero si, en un principio, se trata de una oferta atractiva para la demanda de turismo cultural, lo cierto es que se ha ido forjando de manera espontánea y no planificada en los principales corredores turísticos de la ciudad sin apenas conocimiento real de la demanda turística y las necesidades de los consumidores, por lo que el conocimiento del perfil de estos debería ser una prioridad de investigación, más aún por la opacidad o práctica inexistencia de información estadística y registral y la escasez de estudios específicos a nivel nacional, regional o local en España. En el caso de Córdoba el primer problema al que nos enfrentamos es la suma dificultad de poder determinar la suficiencia de la oferta de estos establecimientos para cubrir la demanda actual y a corto y medio plazo, dado que apenas contamos con datos sobre consumidores reales y potenciales, siendo así difícil plantear una estrategia de marketing y comercialización de la artesanía.

Las políticas de protección y fomento de la artesanía en Andalucía vienen siendo aplicadas por la Consejería de Cultura y la de Empleo, Empresa y Comercio de la Administración Regional, respectivamente, que tienen competencias descentralizadas del Estado español en materia cultural, comercial y de empleo, pero los desencuentros y la falta de vinculaciones efectivas con el sector artesanal vienen siendo frecuentes (Rioja, 2006). El primer organismo ha ampliado en las últimas décadas las figuras de protección y de reconocimiento del patrimonio etnológico como la artesanía, considerada como forma relevante de expresión cultural y modo de vida propio de los territorios, mientras que el segundo se encuentra más imbricado en el desarrollo y fomento económico del sector a través de la Ley 15/2005, de 22 
de diciembre, de Artesanía de Andalucía y sus instrumentos de desarrollo como el II Plan Integral para el Fomento de la Artesanía en Andalucía (2014-2017), que ya plantea el diseño y estructuración de rutas turístico-artesanales; las declaraciones geográficas de Zonas y Puntos de Interés Artesanal; el distintivo Calidad Artesanal de Andalucía; las distinciones individuales para Maestros Artesanos y la línea de subvenciones no reembolsables para modernización y fomento de las pymes y asociaciones artesanales.

En 2014 se declaró el casco histórico de Córdoba como Zona de Interés Artesanal, integrando a un total de 18 talleres de artesanos más orientados hacia el turismo y en su mayoría de oficios del cuero y marroquinería, cerámica y platería-bisutería. Esta marca territorial pretende mejorar la viabilidad de la actividad y mejorar la comercialización de sus productos en áreas de especial concentración de la oferta y señas diferenciales de producción, comercialización y relevancia histórico-cultural. Esta iniciativa fue promovida por la Asociación Cordobesa de Artesanos (ACA), creada en 1986, que solo agrupa a menos del 30\% de los talleres de la ciudad. El hecho de que polarice sus actividades en torno al Zoco Municipal de Córdoba, primer mercado artesanal creado en España, y en la zona de mayor afluencia turística de la Judería-Mezquita Catedral, parece haberle restado interés como interlocutor entre buena parte de los artesanos ubicados en otras áreas urbanas, poco a nada orientados al mercado turístico, que trabajan, en algunos casos, en la economía irregular o sumergida y que suelen contar con escasa capacidad de comercialización. Es esta Asociación, no obstante, la única organización local que ha comenzado a plantear algunas iniciativas recientes, aunque muy embrionarias, para la promoción de la artesanía, como la publicación de un plano-guía de los establecimientos asociados en la ciudad de Córdoba, pero en las entrevistas a realizadas a miembros de esta Asociación se deduce - como señala uno de ellos- que «las relaciones comerciales y colaborativas con empresas y asociaciones del sector turístico local son mínimas y reducidas a contactos con algunos guías turísticos».

\section{Fuentes y METOdOLOGÍA}

La investigación que presentamos se ha realizado a través de un análisis cuantitativo y cualitativo por medio de una encuesta directa a una muestra representativa de talleres y tiendas artesanales de la ciudad, resultando un error muestral de $+/-4,15 \%$, una población de 38 locales, en su mayoría inscritos en el Registro Oficial de Artesanos de Andalucía, y un índice de 
fiabilidad, según el Alpha de Cronbach, de 0,82, que refuerza la validez del trabajo de investigación si tomamos como referencia 0,70 como valor estándar recomendado (Nunnally y Bernstein, 1994). Los datos recogidos fueron organizados, tabulados y analizados usando el programa SPSS 18.0 y para su tratamiento se han utilizado herramientas estadísticas univariantes y bivariantes. Complementariamente se practicaron siete entrevistas en profundidad a expertos y agentes locales (stakeholders) vinculados con el sector artesanal y turístico (agencias receptivas, guías turísticos, directivos de la Asociación de Artesanos y técnicos de la Administración Turística), incluyendo una serie de preguntas semiestructuradas y abiertas que han permitido la obtención de una información cualitativa de interés.

Las encuestas a los establecimientos artesanos se realizaron durante los meses de mayo y junio del año 2017, coincidiendo con la temporada alta turística en Córdoba — cuando se encuentran abiertos en su totalidad- y mediante visitas físicas a los diferentes establecimientos, habiéndose realizado previamente un pre-test de 25 encuestas para detectar posibles deficiencias en el cuestionario. Como algunas preguntas iban en relación directa con las características particulares de estos establecimientos y el merchandising de los productos ofertados, se pudo corroborar directamente la veracidad de las respuestas, además de profundizar in situ en otros aspectos cualitativos de interés a través de preguntas abiertas y comentarios de libre realización por parte de los encuestados.

El cuestionario ha estado compuesto por 28 preguntas agrupadas en tres apartados: 1.) el primero sobre las características de las empresas de artesanía en cuanto a número de empleados, tipología y tamaño, cuyos resultados hemos contrastado y ponderado mediante la explotación específica del Registro Oficial de Artesanos de Andalucía (RADA); 2.) el segundo sobre la situación de la artesanía local, su sostenibilidad, promoción y difusión y las estructuras colaborativas interempresariales e intersectoriales; 3.) y el último apartado sobre la comercialización de los productos artesanales y su vinculación y nivel de integración con la oferta y la actividad turística local. La encuesta, por otro lado, fue realizada en todas las zonas o barrios del Conjunto Histórico de Córdoba con alguna presencia de talleres o tiendas de artesanía, que finalmente hemos cartografiado y georreferenciado a través de diversas fuentes de información (RADA, trabajo de campo, medios de promoción turística, portales de Internet, etc.), con el objeto de interrelacionar las ubicaciones geográficas de estos negocios con su entorno urbanístico, turístico y comercial y establecer sus claves explicativas. 
ANÁLISIS DE RESULTADOS Y DISCUSIÓN

El análisis descriptivo de las encuestas y entrevistas realizadas ha arrojado los siguientes resultados principales:

1) Los establecimientos dedicados a la artesanía están gestionados en un 78 '9\% por autónomos (empresarios individuales) con solo 1 o 2 trabajadores (en más de un $75 \%$ de los casos), un tamaño propio de micropymes familiares y una cierta experiencia en el oficio artesano como mínimo de cinco años $(68,4 \%)$, así como con un buen nivel de profesionalidad.

2) Algo más del $52 \%$ de los establecimientos se concentra en el área de mayor afluencia turística del casco histórico (Figura 1) y particularmente en la zona declarada Patrimonio de la Humanidad del entorno de la Judería y Mezquita-Catedral, barrio de La Ribera y centro comercial del eje Tendillas-La Corredera. En más de un $70 \%$ de los casos localizados en esta área de concentración de flujos turísticos, los talleres no solo disponen de tienda de venta directa al público sino también de alguna pequeña zona habilitada para demostraciones en vivo de su trabajo y atención de visitas. Los establecimientos ubicados en otras zonas del Conjunto Histórico (Ajerquía Norte) son relativamente numerosos pero están muy poco o nada orientados hacia la demanda turística, se dirigen al público local y al consumo más utilitario (zapaterías, esparterías, sastrerías, carpintería, confección de trajes regionales, etc.), o bien tienen otros mercados específicos al margen de la demanda turística como son el religioso (imaginería, orfebrería) o el comercio exterior, minorista y mayorista, de joyería, platería y bisutería. En la Ajerquía, los establecimientos artesanales no orientados al público local y al consumo más doméstico y utilitario, apenas tienen visibilidad de cara a la demanda turística potencial, por ubicarse generalmente fuera de los circuitos turísticos de la ciudad y tener una difícil accesibilidad en el intrincado e irregular callejero de esta zona del Conjunto Histórico, alejada y periférica respecto a la Zona de Afluencia Turística de la ciudad. 
FIGURA 1

LOCALIZACIÓN DE LOS NEGOCIOS ARTESANOS EN EL CONJUNTO HISTÓRICO DE CÓRDOBA

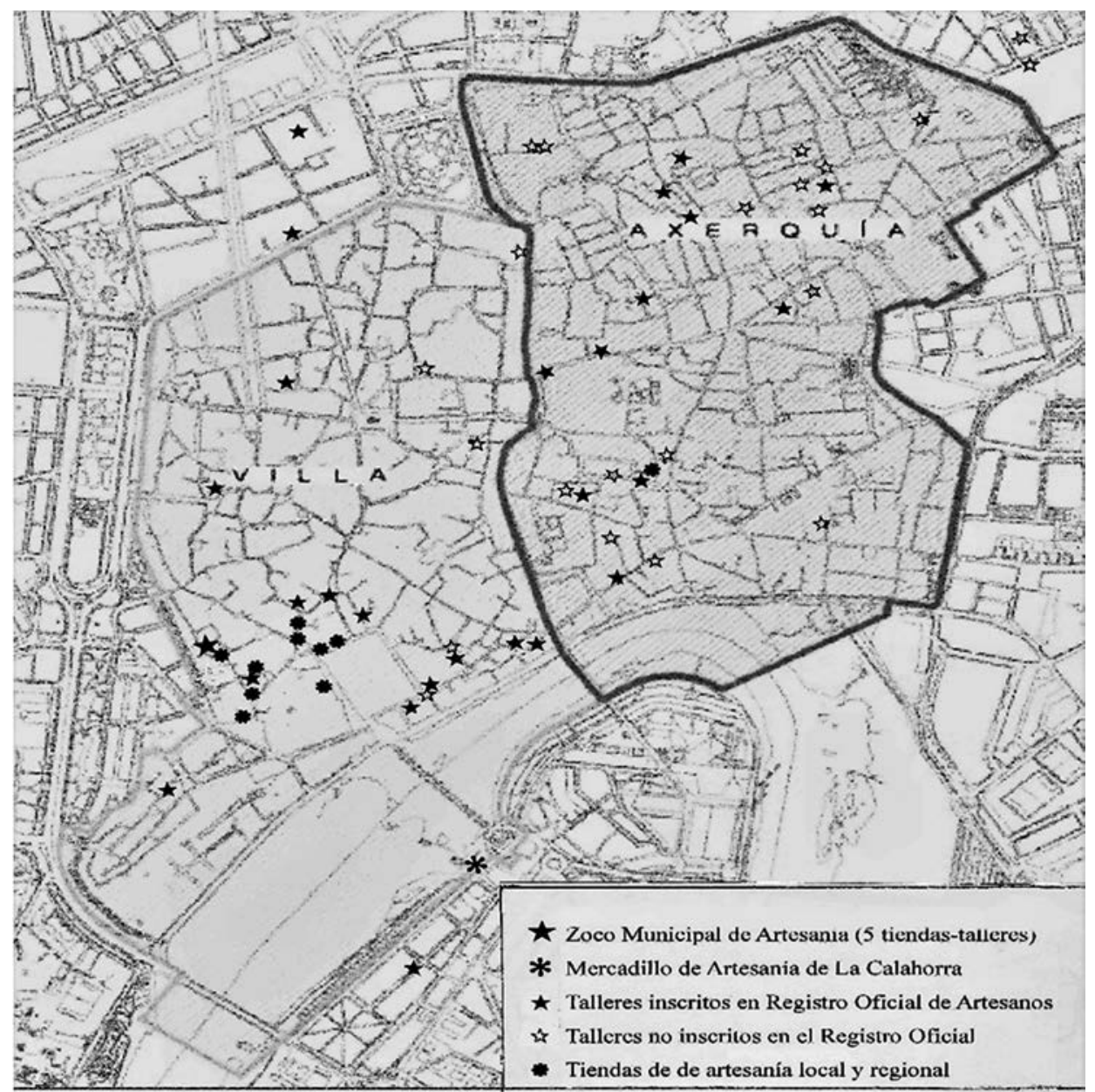

Fuente: Base cartográfica del Plan Especial del Conjunto Histórico de Córdoba (Ayuntamiento de Córdoba). Elaboración propia.

3) Respecto a la demanda turística urbana (Tabla 1), existe una fuerte concienciación por parte de los artesanos sobre la contribución de la oferta y el patrimonio artesanal a la mejora de la satisfacción y experiencia del turista en el destino y al desarrollo turístico de 
la ciudad. Y también, de manera abrumadora, consideran que los turistas saben apreciar el valor cultural e identitario de la artesanía local. Es de destacar cómo casi un $40 \%$ son visitantes extranjeros, frente a solo un $26,30 \%$ de turistas nacionales de fuera de la región, que comprensiblemente se sienten menos atraídos por la artesanía tradicional que posiblemente pueden encontrar y conocer en otros puntos de la geografía española. En cualquier caso, y pese a reconocerse las potencialidades de la artesanía a la atracción de la demanda turística urbana y la mejora de la experiencia de los visitantes, en las entrevistas realizadas a artesanos se coincide mucho en la afirmación de que «actualmente no sabemos llegar a los turistas, nuestros talleres son poco visibles y los turistas no son precisamente nuestros principales clientes»; impresión esta que está sobre todo muy extendida en la zona de la Axerquía.

TABLA 1

DEMANDA TURÍSTICA Y PROCEDENCIA Y NIVEL SOCIOEDUCATIVO DE LOS CLIENTES

\begin{tabular}{|c|c|c|}
\hline Pregunta/cuestión & Respuestas & $\%$ \\
\hline $\begin{array}{l}\text { Contribución de la oferta } \\
\text { artesanal a una mayor } \\
\text { afluencia y satisfacción del } \\
\text { turismo en el casco histórico }\end{array}$ & $\begin{array}{l}\text { Si } \\
\text { No }\end{array}$ & $\begin{array}{l}76,30 \% \\
23,70 \%\end{array}$ \\
\hline $\begin{array}{l}\text { Nivel socioeducativo } \\
\text { de la clientela de los } \\
\text { establecimientos de } \\
\text { artesanía }\end{array}$ & $\begin{array}{l}\text { Sin estudios oficiales. } \\
\text { Estudios primarios } \\
\text { Estudios de Enseñanza Secundaria } \\
\text { Estudios superiores universitarios }\end{array}$ & $\begin{array}{l}13,20 \% \\
13,20 \% \\
55,30 \% \\
18,40 \%\end{array}$ \\
\hline $\begin{array}{l}\text { Procedencia de la clientela } \\
\text { de los establecimientos de } \\
\text { artesanía }\end{array}$ & $\begin{array}{l}\text { De la ciudad de Córdoba. } \\
\text { De la provincia de Córdoba. } \\
\text { De otras zonas de Andalucía. } \\
\text { Del resto de España. } \\
\text { Del extranjero }\end{array}$ & $\begin{array}{l}10,50 \% \\
10,50 \% \\
13,20 \% \\
26,30 \% \\
39,50 \%\end{array}$ \\
\hline
\end{tabular}

Fuente: Encuesta a establecimientos de artesanía (2017), Elaboración propia 
TABLA 2

SOSTENIBILIDAD Y COMPETITIVIDAD DE LOS NEGOCIOS DE ARTESANÍA

\begin{tabular}{|c|c|c|}
\hline Pregunta/cuestión & Respuestas & $\%$ \\
\hline $\begin{array}{l}\text { ¿Cree que es realmente } \\
\text { positivo obtener una } \\
\text { certificación o distintitivo de } \\
\text { calidad y autenticidad de los } \\
\text { productos artesanales? }\end{array}$ & $\begin{array}{l}\text { Si } \\
\text { No }\end{array}$ & $\begin{array}{l}89,50 \% \\
10,50 \%\end{array}$ \\
\hline $\begin{array}{l}\text { ¿Dispone de inscripción en } \\
\text { el Registro de Artesanos, de } \\
\text { adhesión a Zona de Interés } \\
\text { Artesanal y/o de distinto o } \\
\text { certificación de calidad? }\end{array}$ & $\begin{array}{l}\text { Si. Registro y ZIA Junta de Andalucía } \\
\text { Sí. Otros distintivos o certificaciones } \\
\text { No, no me interesa realmente. }\end{array}$ & $\begin{array}{r}71,10 \% \\
0,00 \% \\
28,90 \%\end{array}$ \\
\hline \multirow{3}{*}{$\begin{array}{l}\text { Valoración de la gestión en } \\
\text { materia de sostenibilidad } \\
\text { de la artesanía local } \\
\text { (talleres y tiendas) desde la } \\
\text { perspectiva turística }\end{array}$} & $\begin{array}{l}\text { Buena, se cuida tanto al oficio } \\
\text { artesano como al turista. Queremos } \\
\text { que ambos términos continúen } \\
\text { generando sinergias positivas. }\end{array}$ & $57,90 \%$ \\
\hline & $\begin{array}{l}\text { Regular. Estamos poco implicados en } \\
\text { el sector turístico. }\end{array}$ & $26,30 \%$ \\
\hline & $\begin{array}{l}\text { Nula o inexistente. Nuestro taller no } \\
\text { está orientado hacia el turismo y no } \\
\text { vemos interés en éste como posible } \\
\text { generador de ingresos. }\end{array}$ & $15,80 \%$ \\
\hline $\begin{array}{l}\text { Problemas principales de } \\
\text { continuidad y sostenibilidad } \\
\text { de los negocios }\end{array}$ & $\begin{array}{l}\text { Exceso de oferta y competencia } \\
\text { desleal } \\
\text { Relevo generacional } \\
\text { Falta de ayudas y promoción de las } \\
\text { AAPP } \\
\text { No se aprecian problemas } \\
\text { importantes }\end{array}$ & $\begin{array}{l}34.20 \% \\
28.90 \% \\
23,70 \% \\
13,20 \%\end{array}$ \\
\hline $\begin{array}{l}\text { ¿Es miembro de alguna } \\
\text { Asociación empresarial de } \\
\text { artesanos o de otro tipo? }\end{array}$ & $\begin{array}{l}\text { Si } \\
\text { No }\end{array}$ & $\begin{array}{l}42,10 \% \\
57,90 \%\end{array}$ \\
\hline
\end{tabular}

Fuente: Encuesta a establecimientos de artesanía (2017), Elaboración propia 
4) En cuanto a la sostenibilidad de la actividad (Tabla 2), un $89,5 \%$ de los establecimientos afirman que las certificaciones o distintivos de calidad de los negocios de artesanía pueden contribuir bastante a la captación de clientes y turistas si garantizan la autenticidad y originalidad de los productos artesanales frente a las copias y falsificaciones procedentes de países asiáticos, que suelen proliferar en las tiendas de souvenirs provocando una situación de competencia desleal y una imagen no auténtica, distorsionada y banalizada del patrimonio artesanal. El análisis bivariante realizado obtiene, en este punto, una marcada asociación entre las variables «iconsidera que la artesanía es un factor de incremento y satisfacción del turismo?» y «icree que es un buen argumento de venta el utilizar en la artesanía marcas o certificaciones de calidad?», con un estadístico $\chi^{2}=11,606$ (p-value= 0.003), que indica que para el artesano la acreditación de autenticidad y tipicidad de sus productos les otorga valor añadido y fiabilidad de cara al turista y consumidor final. Concuerda esta opinión con el hecho de que algo más del 70\% de los talleres artesanales se encuentren inscritos en el RADA, estén adheridos a la Zona de Interés Artesanal del Conjunto Histórico y/o cuenten con el distintivo de Maestro Artesano, si bien la única certificación oficial de calidad disponible es el de Andalucía, Calidad Artesanal, que no ha sido regulada hasta el año 2015, de manera que solo un artesano local dispone de la misma y, en cualquier caso, es muy poco conocida y promocionada tanto entre los artesanos como entre los consumidores finales.

La dificultad del relevo generacional en el oficio artesano se revela, por su parte, como el segundo problema en importancia, ya que sus titulares tienen una edad media-alta y sus hijos no suelen verse atraídos por la profesión, detectándose dificultades en la inserción profesional de nuevos artesanos mediante un sistema adecuado de formación-aprendizaje y una mayor vinculación entre los talleres y las dos Escuelas de Artes y Oficios existentes en la ciudad. Por añadidura, es de destacar la valoración bastante negativa que se tiene de la labor de las Administraciones Públicas en cuanto a protección, fomento y apoyo de la artesanía local, sobre todo de la Administración Local. Y, en este sentido, la mayoría de los encuestados (casi un 30\%) entiende que debería ser la Administración turística, conjuntamente con las asociaciones empresariales de artesanos, la que debería de velar en primer término por la promoción y difusión de sus productos. Por otra parte, se advierte la importante descoordinación interadministrativa, solapamientos y disfunciones entre las distintas administraciones, particularmente entre el Patronato Provincial de Turismo, la Delegación de Turismo del Ayuntamiento y la Administración Regional. 
Con respecto a la integración y participación colaborativa de los artesanos en asociaciones, redes interempresariales o clubes de producto, destaca el desinterés general manifestado, de manera que el 58\% de los encuestados reconocen no pertenecer a ninguna organización y como mucho están asociados únicamente a la Asociación local de artesanos, lo que revela un importante individualismo y aislamiento funcional de estas micropymes.

TABLA 3

ACCIONES DE PROMOCIÓN Y COMERCIALIZACIÓN TURÍSTICA DE LA ARTESANÍA LOCAL

\begin{tabular}{|c|c|c|}
\hline $\begin{array}{l}\text { ¿Colabora con algún agente } \\
\text { turístico de la ciudad o } \\
\text { ha participado en alguna } \\
\text { actuación de promoción } \\
\text { turística? }\end{array}$ & $\begin{array}{l}\text { Si } \\
\text { No. No tengo relación con el sector } \\
\text { turístico local }\end{array}$ & $\begin{array}{l}44,70 \% \\
55,30 \%\end{array}$ \\
\hline $\begin{array}{l}\text { ¿Está bien promocionada la } \\
\text { artesanía desde el punto de } \\
\text { vista turístico en la ciudad } \\
\text { de Córdoba? }\end{array}$ & $\begin{array}{l}\text { Si } \\
\text { No }\end{array}$ & $\begin{array}{l}13,20 \% \\
86,80 \%\end{array}$ \\
\hline $\begin{array}{l}\text { ¿Ve bien la creación de } \\
\text { un Museo/Centro de } \\
\text { Interpretación deArtesanía } \\
\text { en Córdoba? }\end{array}$ & $\begin{array}{l}\text { Si } \\
\text { No }\end{array}$ & $\begin{array}{r}97,40 \% \\
2,60 \%\end{array}$ \\
\hline \multirow{5}{*}{$\begin{array}{l}\text { Actuaciones concretas para } \\
\text { la difusión, valorización } \\
\text { y comercialización de la } \\
\text { artesanía cordobesa }\end{array}$} & $\begin{array}{l}\text { Tienda y exposiciones de artesanía } \\
\text { en Centro de Recepción de } \\
\text { Visitantes }\end{array}$ & $60,50 \%$ \\
\hline & $\begin{array}{l}\text { Zocos y Mercadillos de venta en } \\
\text { espacios estratégicos del casco } \\
\text { histórico }\end{array}$ & $42,10 \%$ \\
\hline & $\begin{array}{l}\text { Exposiciones itinerantes: galerías, } \\
\text { edificios públicos e histórico- } \\
\text { artísticos, etc. }\end{array}$ & $55,30 \%$ \\
\hline & $\begin{array}{l}\text { Central de compras que visibilice la } \\
\text { oferta }\end{array}$ & $42,10 \%$ \\
\hline & Rutas turístico-artesanales & $57,90 \%$ \\
\hline
\end{tabular}

Fuente: Encuesta a establecimientos de artesanía (2017), Elaboración propia 
5) En cuanto a la participación en acciones de promoción y comercialización de la artesanía como producto turístico (Tabla 3), solamente el 28,9\% de los encuestados afirmaron que pertenecían a alguna ruta turísticocultural, pero, en realidad, mayoritariamentese refirieron a su pertenencia a la Asociación Cordobesa de Artesanos (ACA), que recientemente ha editado un plano guía de la oferta artesanal de la ciudad como punto de partida para el diseño e implementación de un futuro itinerario. Y, aún cuando hay dos empresas locales de guías de turismo interesadas en la comercialización de una ruta temática artesanal, todavía no han podido hacerse realidad por diversos problemas de adecuación funcional de los talleres y horarios de visitas y falta de apoyo promocional de las entidades públicas de turismo. La ausencia de información en las Oficinas de Turismo, webs y portales turísticos oficiales sobre la oferta artesanal agrava más aún esta situación, como también las escasas sinergias interempresariales entre los negocios de artesanía, los establecimientos turísticos de alojamiento y de restauración y otros servicios turísticos de la ciudad, manifestándose un fuerte aislamiento funcional y un comportamiento estanco que refleja la escasa integración del sector artesanal con el sector de hostelería, comercio y turismo.

En las encuestas, por último, se preguntó sobre posibles acciones para mejorar las sinergias colaborativas turismo-artesanía-comercio. En este punto la apertura de un centro de interpretación de artesanía o un museo es vista positivamente por el $97,40 \%$ de los encuestados y también se apoyan otras medidas como la instalación de una tienda y exposiciones itinerantes en el Centro de Visitantes del casco histórico — en la actualidad infrautilizado y sin apenas equipamiento interpretativo-, la habilitación de mercadillos y zocos en espacios públicos estratégicos y la puesta en marcha de rutas turísticoartesanales.

\section{Conclusiones}

Los negocios de artesanía de la ciudad de Córdoba cuentan en general con unas expectativas positivas de negocio derivadas muchas veces del desarrollo turístico, pero aún poco desarrolladas y optimizadas por la existencia de algunos problemas y debilidades que constriñen su consolidación, como es el escaso conocimiento del sector turístico por parte de los artesanos, las dificultades de 
adecuación de sus establecimientos a las exigencias de la demanda turística y la falta de apoyo público mediante estrategias de sostenibilidad. El turismo relacionado con el consumo de productos artesanos es, en cualquier caso, una oferta cualificada que puede complementar y enriquecer al turismo cultural y patrimonial de la ciudad, pese a lo cual no está siendo objeto de puesta en valor de manera planificada y sustantiva. Se echa en falta, en fin, una auténtica gestión estratégica público-privada que procure una integración funcional entre la artesanía, el turismo y el comercio local.

El hecho de que la gran mayoría de los talleres y tiendas de artesanía tengan una estructura de micropymes, estén regentados por empresarios individuales conformando un tejido productivo muy atomizado y cuenten con escasos recursos humanos y materiales y medios propios, hace difícil aplicar estrategias de sostenibilidad en sus negocios, a lo que se suma una cada vez mayor dependencia de una demanda turística local muy estacional y potencialmente fluctuante por factores externos e internos de todo tipo, la competencia desleal de productos falsificados, de imitación y de mala calidad y las actuaciones descoordinadas — cuando existen - poco sustantivas o escasamente proactivas de fomento, promoción y comercialización de las Administraciones Públicas con competencias en materia de comercio y turismo. Y estos problemas de sostenibilidad se agudizan en la medida en que existe un importante aislamiento funcional de estos establecimientos con respecto a otros agentes locales que participan e inciden en la cadena turístico-comercial de la ciudad, pese a que en su mayoría se localizan en la zona de mayor afluencia turística del Conjunto Histórico.

El desarrollo y la consolidación de los destinos de turismo cultural están directamente relacionados con la gestión de los establecimientos, servicios y recursos patrimoniales que les sirven de soporte, y, por tanto, dependen del buen funcionamiento de las relaciones entre actores en la cadena de producción y comercialización de los productos artesanales y su capacidad de generar un producto turístico atractivo. Esto unido a la calidad del entorno cultural y patrimonial, puede convertirse en un elemento diferenciador que permita al destino obtener una posición competitiva respecto a otros territorios. Pero para ello los actores artesanales han de realizar importantes esfuerzos para ofrecer una experiencia de calidad y mantener su capacidad de atracción turísticocomercial, de manera que han de estar cada vez más abiertos a la colaboración con otras ofertas, entidades y agentes de otros sectores de actividad, al tiempo que más próximos a la lógica empresarial y comercial, teniendo en cuenta la preocupación existente por los problemas de viabilidad, financiación y rentabilidad de sus negocios. 
La producción y la oferta efectiva de turismo vinculada a la artesanía exige la integración de un complejo rango de actividades y servicios dentro y entre una serie de unidades de producción (empresas, establecimientos, actividades, equipamientos, sistemas de producción y comercialización, etc.) que contribuyan a la creación de valor (Clocke, Crang y Goodwin, 2011). Esto implica su adaptación especial a las exigencias de la función turística para aumentar su capacidad de influencia y capacidad de reclamo para los turistas, lo que también, a su vez, puede beneficiar la atracción de la demanda del público local.

La pérdida de oportunidades se produce al no estar debidamente integrados y ensamblados el sector artesanal con la ciudad y la oferta turístico-cultural y de ocio (rutas y excursiones, agenda de eventos culturales y comerciales, recursos patrimoniales, equipamientos e infraestructuras turísticas, servicios de guías, materiales e instrumentos de promoción turística ). En consecuencia, se hace necesaria la redefinición de la estrategia comercial y de sostenibilidad de los negocios de artesanía. Y por ello planteamos finalmente en este trabajo algunas medidas contrastadas y validadas con los propios agentes locales y expertos: 1.) Una mayor profesionalización de los comerciantes y un mejor conocimiento del sector turístico local que afiance su interacción y sinergias con este y mejore la atención al cliente, así como su orientación funcional hacia la demanda turística, lo que permitiría diversificar y desestacionalizar la clientela, además de favorecer la fidelización del cliente y la individualización del acto de venta; 2.) una integración funcional con el sector de la hostelería y el turismo de la ciudad, tanto a nivel interempresarial como de colaboración mutua con las Administraciones con competencias en fomento y promoción del turismo, dadas las potencialidades de la artesanía como valor añadido del turismo cultural; 3.) la promoción de los establecimientos y productos artesanales bajo el paraguas de la marca geoturística de Córdoba y una planificación turístico-comercial conjunta de aquellas acciones de interés mutuo para ambos subsectores, incluyendo acciones concretas de cierto valor demostrativo y efectos de arrastre como la habilitación de zocos y mercadillos en espacios públicos estratégicos, exposiciones itinerantes, rutas turístico-culturales, central de compras, etc.

\section{BibLIOGRAFÍA}

Afra, M. (2016): "Examine the relationship crafts with tourism development in Lorestan province", International Journal of Advanced Biotechnology and Researchs, $7 / 4$, pp. 382-387. 
Ashley, C., Roe, D. y Goodwin, H. (2001): Pro-poor Tourism Strategies: Making Tourism Work for the Poor, London, Overseas Development Institute, ODI/International Institute for Environment and Development/University of Greenwich/Centre for Responsible Tourism, CRT.

Baksi, A. K. (2015a): "Craftourism: moderating emotional-bonding with destination and its loyalty", Asia-Pacific Journal of Innovation in Hospitality and Tourism, 4/2, pp. 159-179.

Baksi, A. K. (2015b): "Moderating Effects of Craftourism on Place Attachment and Destination Loyalty", Journal of Indonesia Tourism and Development Studies, 3/4, pp. 71-84.

Ballester, R. (1996): "La artesanía y las pequeñas empresas: claves del crecimiento y el empleo en Europa", Revista Valencia de Estudios Autonómicos, 16, pp. 349-352.

Benítez, S. (2010): "La artesanía latinoamericana como factor de desarrollo económico, social y cultural", Revista Cultura y Desarrollo, 6, pp. 3-19.

Bouchart, D. (2004): Indice UNESCO Artesanía-Turismo, París, UNESCO.

Clocke, P., Crang, P. y Goodwin, M. (2011): Introducing Human Geographies, London, Arnold.

Duond, N. (2015): "Tourism, Traditional Handicrafts, and Community Economic Development: A Value Chain Analysis of Phuoc Tich Heritage Village, Vietnam", tesis doctoral inédita, Auckland, University of Technology.

Essayad, A. (2011): "Design and implementation of a platform for location based services: a case study of GIS of archaelogical and handicraft of Fez Medina", International Journal of Computer Sciencie Issues, 8/5, pp. 524-530.

Escuela de Organización Industrial (2014): Plan estratégico de Turismo de Córdoba 2015-2019, Córdoba, Ayuntamiento de Córdoba.

Espinosa, A. (2009): "Estrategias de complementariedad entre comercio y turismo en centros históricos patrimoniales: el caso de Venecia", Boletín de la Asociación de Geógrafos Españoles, 50, pp. 281-296.

Fernández, G. y Ramos, A. G. (2005): "Patrimonio industrial y rutas turísticas culturales: algunas propuestas para Argentina", Cuadernos de Turismo, 15, pp. 97-112.

Fernández de Paz, E. (2014): "Políticas de fomento de la artesanía chilena: maridaje entre artesanía y turismo". En Prats, J. (Ed.): Periferias, fortalezas y diálogos, Chile, FAAEE, pp. 2150-2180.

Freire, E. (2004): "La recuperación de la alfarería tradicional en la provincia de Lugo: procesos socioeconómicos y culturales", tesis doctoral inédita, Santiago, Universidad Santiago de Compostela.

Gazimagomedov, G. (2017): "The role of folk arts and crafts of Dagestan in consolidating and expanding the tourist-excursion routes”, Ug Rossi: Èkologià, Razvitìe, 12/1, pp. 161-175.

González, R. (2003): "Artesanía y desarrollo sostenible en Sevilla”, Cuadernos de Economía de la Cultura, 2, pp. 13-28.

Gustami, S.P., Kusuma, L. y Heru, A. (2014): "Craft Arts and Tourism in Ceramic Art Village of Kasongan in Yogyakarta", Journal of Arts \& Humanities, 3/2, pp. 37-49. 
Hall, C. M. y Page, S. J. (1999): The Geography of Tourism and Recreation: environment, place and space, London, Routledge.

Hernández, R. (2002): "Turismo y patrimonio en el Sur de Tenerife: a propósito de la industria artesanal de la cal", El Pajar. Cuadernos de Etnografía Canaria, 11, pp. 42-53.

Hernández-Girón, J. D., Yexcas, M. y Domínguez-Hernández, M. L. (2007): "Factores de éxito en los negocios de artesanía en México", Estudios Gerenciales, 23/104, pp. 77-99.

Hirotsugu, S. (2005): "Protection of Intangible Cultural Heritage in Japan", en SubRegional Experts Meeting in Asia on Intangible Cultural Heritage, Bangkok, Unesco, pp. 1-14.

Holder, J. (1989): "Tourism and the future of Caribbean handicraft", Tourism Management, 10/4, pp. 310-314.

Horjan, G. (2011): "Traditional crafts as a new attraction for Cultural Tourism. Zagreb (Croacia)". International Journal of Intangible Heritage, 6, pp. 45-56.

Instituto de Turismo de Murcia (2007): El producto de artesanía para el Turismo en la Región de Murcia, Murcia, Gobierno Autónomo de Murcia.

International Trade Centre (2010): Inclusive Tourism: Linking the Handicraft Sector to Tourism Markets, Geneva, ITC.

Iuva de Mello, C. y Ciliane, C. (2015): "El souvenir artesanal y la promoción de la imagen del lugar turístico", Estudios y Perspectivas en Turismo, 14, pp. 188-204.

Jha, G. y Nath, G. (2015): "Koth (Grass Mat) craft of Baruajani village as potential ingredient: project and display", Indian Streams Research Journal, 5/1, pp. 1-6.

Kosianski, J.-M. (2005): "Itinéraires touristiques de quatre artisans d'art", Espaces. TourismeELoisirs, 232, pp. 14-22.

MacCannell, D. (1984): "Reconstructed ethnicity tourism and cultural identity in third world communities", Annals of Tourism Research, 11/3, pp. 375-391.

Maruya, K., Yameshita, S. y Uchiyama, T. (2015): "Community spaces in the minds of traditional craftsmen in a pottery village in Japan", Frontiers of Architectural Research, 4/4, pp. 253-262.

Mincomercio (2006): Política de Turismo y Artesanía: iniciativas conjuntas para el impulso y la protección del patrimonio artesanal y el turismo colombiano, Bogotá, Ministerio de Comercio, Industria y Turismo.

Nason, J. D. (1984): "Tourism, handicrafts, and ethnic identity in Micronesia", Annals of Tourism Research, 11/3, pp. 421-449.

Nunnally, J. C. y Bernstein, J. H. (1994): Psychometric Theory, New York, McGraw-Hill. Oliveira, D., Pasquotto, M. A., Sauer, L., Gomes, T. y Casthilo, M. A. (2013): “Artesanato com Lã de Ovinos, Turismo e Desenvolvimento Local", Pasos. Revista de Turismo y Patrimonio Cultural, 11/4, pp. 661-670.

OMT [Organización Mundial del Turismo] (2008): Tourism and handicrafts: A report on the international conference on tourism and handicrafts, 13-15 May 2006, Madrid, World Tourism Organization. 
Perlès, V. (2007): "Lartisan face au tourisme: un passeur d'espaces et de temps", Espaces et sociétés, 128-129, pp. 201-214.

Prost, E. y Givre, O. (2005): "Le Haut-Jure, terre de savoir-faire", Espaces. Tourisme $\mathcal{E}$ Loisirs, 232, pp. 48-52.

Richards, G. (2013): Developing and Marketing Crafts Tourism. The EUROTEX Project. Tilburg, Universidad de Tilburg, Department of Leisure Studies.

Rioja, C. (2006): "Artesanía y administración: encuentros y desencuentros", Boletín del Instituto Andaluz del Patrimonio Histórico, 591, pp. 76-85.

Rivera, M. L., Alberti, P., Vázquez, V. y Mendoza, M. (2008): "La artesanía como producción cultural susceptible de ser atractivo turístico en Santa Catarina del Monte, Texcoco", Convergencia: Revista de Ciencias Sociales, 46, pp. 225-247.

Froehlich, J. M. y Alves, H. F. I. (2007) "Novas identidades, novos territórios: Mobilizando os

recursos culturais para o desenvolvimento territorial", Revista Extensão Rural, 14, pp. 65-90.

Rodrigues, B.; Sousa, R. y Vasconcelos, V. (2014): "Produçao artesanal associada ao turismo em Elha Grande de Santa Isabel (Parnaíba-Pi), Cultur. Revista de Cultura e Turismo, 8 (2), 137-156.

Rodríguez, E. (2006): "Artesanos del siglo XXI", Revista Emprendedores, 104, pp. 114 119.

Santana, R. y Ricci, F. (2009): "Desenvolvimento turístico sustentável: o artesanato local como alternativa na cidade de San Antônio do Pinhal", Revista de Cultura e Turismo, 3/1, pp. 92-110.

Terziyska, I. (2003): "Traditional crafts and tourism in Bulgaria", en Convention for the Safeguarding of the Intangible Cultural Heritage, Blegoevgrad (Bulgaria), UNESCO, s. p.

Tresserras, J. (2008): El turismo como agente para el rescate y el fortalecimiento del patrimonio cultural y el desarrollo artesanal, Barcelona, Universidad de Barcelona.

Uribe, A. P. (ed.) (2011): Caracterización del sector artesanal latinoamericano, Barranquilla, Universidad Simón Bolívar.

Virassamy, C. y Levêque, J. (2005): "Métiers d'art et tourisme. Des attirances réciproques", Espaces. Tourisme E Loisirs, 231, pp. 22-30.

Vizcaíno, M. L. (2015): "Evolución del turismo en España: el turismo cultural", International Journal of Scientific Management and Tourism, 1/4, pp. 75-95.

Yang, S. (2006): "The successful use of handicrafts in Guizhou Province for poverty alleviation", en International Conference on Tourism and Handicrafts, Tehran, World Tourism Organization, pp. 51-59.

Fecha de recepción: 12 de septiembre de 2017.

Fecha de aceptación: 30 de octubre de 2018. 